University of Nebraska - Lincoln

DigitalCommons@University of Nebraska - Lincoln

Faculty Publications, Department of Psychology

Psychology, Department of

2020

\title{
Moving beyond executive functions: Challenge preference as a predictor of academic achievement in elementary school
}

\author{
Michael J. Sulik \\ Stanford University, michael.sulik@stanford.edu \\ Jenna E. Finch \\ University of Nebraska - Lincoln, jenna.finch@unl.edu \\ Jelena Obradović \\ Stanford University, jelena.obradovic@stanford.edu
}

Follow this and additional works at: https://digitalcommons.unl.edu/psychfacpub

Part of the Child Psychology Commons, Developmental Psychology Commons, Educational

Assessment, Evaluation, and Research Commons, and the Educational Psychology Commons

Sulik, Michael J.; Finch, Jenna E.; and Obradović, Jelena, "Moving beyond executive functions: Challenge preference as a predictor of academic achievement in elementary school" (2020). Faculty Publications, Department of Psychology. 1029.

https://digitalcommons.unl.edu/psychfacpub/1029

This Article is brought to you for free and open access by the Psychology, Department of at DigitalCommons@University of Nebraska - Lincoln. It has been accepted for inclusion in Faculty Publications, Department of Psychology by an authorized administrator of DigitalCommons@University of Nebraska - Lincoln. 


\title{
Moving beyond executive functions: Challenge preference as a predictor of academic achievement in elementary school
}

\author{
Michael J. Sulik, ${ }^{1}$ Jenna E. Finch, ${ }^{2}$ \& Jelena Obradović ${ }^{1}$
}

1 Graduate School of Education, Stanford University, Stanford, CA 94305, USA

2 Department of Psychology, University of Nebraska-Lincoln, Lincoln, NE 68588, USA

Corresponding author: M. J. Sulik, michael.sulik@stanford.edu

\begin{abstract}
Intrinsic motivation and executive functions (EFs) have been independently studied as predictors of academic achievement in elementary school. The goal of this investigation was to understand how students' challenge preference (CP), an aspect of intrinsic motivation, is related to academic achievement while accounting for EFs as a confounding variable. Using data from a longitudinal study of 569 third-, fourth-, and fifth-graders (50\% female), we tested students' self-reported $\mathrm{CP}$ as a predictor of mathematics and English language arts (ELA) achievement in multilevel models that controlled for school fixed effects and student demographic characteristics. CP was positively associated with mathematics and ELA over and above the set of covariates and EFs. While also controlling for prior achievement, $\mathrm{CP}$ continued to explain a small amount of unique variance in mathematics, but not in ELA. These results underscore the importance of including measures of students' intrinsic motivation, in addition to EFs, to obtain a comprehensive understanding of academic success.
\end{abstract}

Keywords: Challenge preference, Executive functions, Academic achievement, Elementary school, Longitudinal, Self-regulated learning

Published in Journal of Experimental Child Psychology 198 (2020), 104883.

DOI: $10.1016 /$ j.jecp.2020.104883

Copyright (C) 2020 Elsevier Inc. Used by permission.

Submitted 10 October 2019; revised 23 April 2020. 


\section{Introduction}

Executive functions (EFs), the higher-order cognitive skills that support goal-directed activities and self-regulation, have been extensively studied as predictors of academic achievement (Zelazo, Blair, \& Willoughby, 2016). EFs are associated with learning-related classroom behaviors (Nelson et al., 2017) and have been identified as robust longitudinal predictors of academic achievement (Fuhs, Farran, \& Nesbitt, 2015; Nguyen \& Duncan, 2019). Yet research relating EFs to achievement has largely ignored the role of motivation (Howse, Lange, Farran, \& Boyles, 2003), despite strong evidence that motivation plays a crucial role in student learning (Eccles \& Wigfield, 2002). For example, intrinsic motivation - which refers to an individual's desire to participate in an activity because it is enjoyable in and of itself-underpins the pursuit of long-term goals (e.g., Wrzesniewski et al., 2014) and is positively related to academic achievement (Corpus \& Wormington, 2014).

In this study, we focused on challenge preference (CP), an aspect of intrinsic motivation that refers to an individual's preference for challenging (as opposed to easy) activities (Harter, 1981). CP is a distinct construct that plays a crucial role in influential theories of learning and achievement. In Elliott and Dweck's (1988) achievement goal theory, challenge seeking (particularly in response to failure) is a key feature of learning goals that promote growth in achievement. Learning goals are characterized by a mastery orientation, in which individuals seek to increase their skills even if it means risking failure. In contrast, a performance orientation is characterized by an avoidance of challenging tasks, so as not to appear incompetent. Mastery orientation is positively associated with better learning outcomes (Huang, 2012).

Consistent with achievement goal theory, CP is positively associated with teachers' perceptions of elementary school students' learning-related classroom behaviors (Finch \& Obradović, 2017). Moreover, previous research shows that students' self-reported CP (which has often been combined with other aspects of intrinsic motivation) has small to moderate associations with grade point average and standardized academic achievement test scores in elementary and middle school (Altermatt \& Pomerantz, 2005; Broussard \& Garrison, 2004; Goldberg \& Cornell, 1998; Lepper, Corpus, \& Iyengar, 2005; Soto, 1988). 
However, longitudinal associations between $\mathrm{CP}$ and academic achievement have been understudied. We were able to identify a single empirical study investigating this relation, and that study was underpowered to detect the small effect sizes that are typical for predictors of change in academic achievement. In that study of 93 adolescents, self-reported $\mathrm{CP}$ was not significantly related to change in academic achievement between fifth and seventh grades (Bronstein, Ginsburg, \& Herrera, 2005).

Moreover, no study has examined associations between $\mathrm{CP}$ and academic achievement while controlling for known associations between EFs and achievement. Consistent with the model of self-regulated learning, EFs and motivational processes are each believed to support academic learning (Zimmerman \& Schunk, 2011). In other words, a student's "will" (motivation) and "skill" (EFs) independently contribute to learning-related classroom behaviors (McCombs \& Marzano, 1990). To successfully learn new academic content, students must be "active participants" in their learning by engaging cognitively, motivationally, and behaviorally during classroom activities (Zimmerman, 1986, p. 308). CP motivates students to seek out opportunities to learn that extend beyond their current abilities, whereas EFs support students' abilities to stay on task, ignore distractions, control impulses, and shift flexibly between different ideas while engaging with learning-related challenges. Theoretically, students' CP supports choosing to engage in self-regulated behaviors that are crucial for classroom learning (McCombs \& Marzano, 1990).

There is limited evidence that $\mathrm{CP}$ and other aspects of intrinsic motivation contribute to academic success over and above EFs. For example, we have previously reported unique effects of self-reported $\mathrm{CP}$ on teachers' reports of classroom behaviors (e.g., frustration tolerance, on-task behavior) while controlling for EFs in elementary school students (Finch \& Obradović, 2017). Further, one study using a small sample of early elementary school students found that teachers' reports of student motivation contributed to reading achievement while controlling for an earlier measure of vocabulary and EFs (Howse et al., 2003). However, no study has examined how students' self-reported CP is linked to standardized assessments of academic achievement or has examined these constructs during middle childhood. 
Third grade marks a significant change in children's schooling experiences, driven by the onset of standardized testing and a shift from basic reading instruction ("learning to read") to independent reading with a goal of learning content ("reading to learn"; Felton \& Akos, 2011). Further, as children enter middle childhood, they are increasingly expected to regulate their behavior and monitor their progress on classroom tasks and assignments. Due to these new academic demands and behavioral expectations, many students struggle during the upper elementary school years and fall behind their peers academically (Annie E. Casey Foundation, 2010; Miles \& Stipek, 2006). CP is particularly relevant during middle childhood, when children encounter more difficult schoolwork. Academic success and mastery goal orientation during the upper elementary school years are also associated with a positive transition to middle school (Anderman \& Midgley, 1997; Tuominen-Soini, Salmela-Aro, \& Niemivirta, 2012). This makes elementary school a particularly relevant developmental period for investigating prospective, longitudinal relations between $\mathrm{CP}$ and academic achievement. Given the high longitudinal stability of academic achievement, it is important to determine whether $\mathrm{CP}$ can predict changes in students' achievement and, thus, serve as a potential target for academic intervention.

\section{The current study}

We extended previous studies by testing the prospective longitudinal relations between student reports of $\mathrm{CP}$ and standardized achievement test scores in mathematics and English language arts (ELA). To understand unique associations of $\mathrm{CP}$ with academic achievement, we estimated a set of models that do not and do control for students' EFs. The purpose of these analyses was to reveal the strength of the relation between $\mathrm{CP}$ and achievement at a single point in time in elementary school and to show how much these relations are reduced when accounting for EFs, which are one of the most robust correlates of academic achievement. To understand the role that $\mathrm{CP}$ plays in predicting longitudinal change in achievement over a 2-year period, we estimated a second set of models in which we also controlled for prior achievement test scores. 


\section{Method}

Participants and procedures

Participants in this study were 569 socioeconomically and ethnically diverse elementary school students (188 third-graders, 258 fourthgraders, and 123 fifth-graders) recruited from two public school districts (eight schools; 33 classrooms) in the San Francisco Bay Area on the U.S. West Coast. The percentage of students meeting or exceeding proficiency standards at these schools was 58\% $(S D=19 \%)$ for mathematics and $69 \%(S D=14 \%)$ for ELA. At these schools, a sizable percentage of students were eligible for free or reduced-price lunch ( $M=42 \%, S D=23 \%)$ and were classified as English language learners $(M=39 \%, S D=19 \%)$. Student ages ranged from 8.00 to 12.29 years $(M=9.88$ years, $S D=0.83)$, and $50 \%$ of the students were female. Racial/ethnic composition of the sample was as follows: $34 \%$ Asian/Pacific Islander, 31\% Latinx/Hispanic, 23\% White/Caucasian, 6\% Black/African American, and 6\% other/multiracial.

All study procedures were approved by the Stanford University Institutional Review Board and by the participating school districts. We obtained a waiver of consent for the classroom-based assessments and written parental informed consent to access administrative school records, which included achievement test data. Students were sampled at the classroom level within participating schools. Of the 813 students who were invited to participate in the study, 70\% of parents gave informed consent for access to administrative school records. Data used in this longitudinal study were collected at three different times, each spaced approximately 1 year apart. First, initial standardized achievement tests were collected in the spring of 2013. Second, students' CP and EFs were assessed by the researchers in the spring of 2014. Third, follow-up standardized achievement tests were collected again in the spring of 2015 .

\section{Measures}

\section{Challenge preference}

Students reported on their CP using a 5-question measure (Developmental Studies Center, n.d.). Each question asked students to choose 
between an easy scenario and a more challenging scenario (e.g., "I like a puzzle that is easy to solve" vs. "I like a puzzle that takes hard work to solve") and was coded as a binary variable (o = easy, 1 = challenging). The content of this scale included two items about puzzles, two items about games, and one item about a hard problem. In contrast to Harter's (1981) challenge preference scale, none of the content was specific to an academic setting. We averaged the items for this scale to create a composite score, ordinal $a=.83$ (Gaderman, Guhn, \& Zumbo, 2012). On average, students reported a preference for challenging activities $(M=0.73, S D=0.29$, range $=0-1)$.

\section{Executive functions}

We employed two independent measures of students' EFs. Direct assessments are considered to be more objective than teachers' reports, but they are less ecologically valid (Toplak, West, \& Stanovich, 2013). In contrast, teachers' reports can be biased by students' demographic characteristics such as gender and race/ethnicity (Garcia, Sulik, \& Obradović, 2019), but they have the advantage of capturing students' EF behaviors as they occur in naturalistic learning contexts. The inclusion of both types of assessments provides a more comprehensive and robust way to capture students' EF skills.

Direct assessments. Four widely used, developmentally appropriate tasks were used to directly assess students' EF skills. Group-based assessments were used to minimize disruption for teachers and students. The tasks were simultaneously administered to all students in each classroom using tablet computers, which has been shown to be as valid and reliable as individual administration of the same tasks (Obradović et al. 2018). Relative to individual assessments, these group-based assessments may have greater ecological validity because they occur in a naturalistic classroom setting. The EF tasks were presented in a fixed order and included (a) the Multi-Source Interference Test (Bush \& Shin, 2006; $a=.81$ ), a measure of inhibitory control; (b) Hearts \& Flowers (Davidson, Amso, Anderson, \& Diamond, 2006), a measure of inhibitory control and cognitive flexibility; (c) Flanker, also a measure of inhibitory control and cognitive flexibility (Zelazo et al., 2013); and (d) Digit Span Backward (Flanagan \& Kaufman, 2009), a measure of working memory. Hearts \& Flowers 
and Flanker each included two blocks of test trials. Cronbach's a values ranged from .58 (Digit Span Backward) to .81 (Multi-Source Interference Test). Based on results of confirmatory factor analysis (Sulik \& Obradović, 2018), accuracy scores were first aggregated within the Hearts \& Flowers task and within the Flanker task, and then scores were standardized and averaged across the four tasks to create an EF composite score $(a=.67)$.

Teachers' reports. To obtain teachers' perceptions of student EFs, we asked each teacher to rank the students on the teacher's class roster based on how well they exemplified a vignette describing a student with good EF skills (see the Appendix; Sulik \& Obradović, 2018). The statements that make up the vignette assess all three components of EFs-inhibitory control, cognitive flexibility, and working memory-and emphasize behaviors that can be easily observed by teachers and that are relevant to learning. We reversed the ranking scores so that high scores would indicate better EFs, and we converted the ranks to percentiles to adjust for differences in classroom size. We applied a probit transformation to the ranking scores to normalize their distribution.

\section{Academic achievement}

Students' mathematics and ELA achievement were measured using standardized achievement tests administered by the State of California. In the spring of 2013, the California Standards Test (CST) was used (Educational Testing Service, 2014). In the spring of 2015, following the adoption of the Common Core State Standards, the Smarter Balanced Assessment Consortium (SBAC, 2016) was used. Item response theory was used to score these tests. Reliability in the population of California students was excellent; depending on grade and content area, CST reliability (a) ranged from .93 to .95 and SBAC reliability $(q)$ ranged from .91 to .93.

\section{Covariates}

Parental years of education, child gender, child race/ethnicity, and child age were obtained from school administrative data. Parental years of education was included as a covariate because of socioeconomic disparities in both EFs and achievement (Lawson, Hook, 
Hackman, \& Farah, 2014; Reardon, 2011). Child gender and child race/ ethnicity were included as covariates due to previous research demonstrating gender and racial/ethnic differences on teacher-reported EFs (Garcia et al., 2019). Finally, child age was included as a covariate because it is associated with better EFs (Lee, Bull, \& Ho, 2013) and less CP (Lepper et al., 2005).

\section{Subsample representativeness}

To evaluate the representativeness of our subsample compared with the larger study sample, we tested whether there were differences on study variables that were not drawn from school records between students with $(n=569)$ and without $(n=244)$ consent for school records. We were not able to test for differences in achievement variables because these scores were available only for students with consent for school records. CP, gender, and age were not significantly associated with parental consent to access school records. There were two significant differences among the seven measures of EFs, namely that teacher-reported EFs, $t(759)=4.90, d=0.40$, and Digit Span Backward performance, $t(707)=2.60, d=0.22$, were better in the group with parental consent to access school records.

\section{Missing data and attrition}

Missing data percentages in our analytic subsample ranged from $\mathrm{o} \%$ for age and gender to $16 \%$ for parent educational attainment. A total of 37 students (7\%) were missing academic achievement scores in 2013. Students were more likely to have missing achievement data in 2013 if they were African American/Black, $t(564)=4.01, p<.001$, or other/multiracial, $t(564)=3.56, p<.001$ (relative to White/Caucasian students); if they had higher math test scores, $t(483)=3.83$, $p<.001$, and reading test scores, $t(482)=3.37, p<.001$, in 2015; if they were rated by teachers as having worse EFs, $t(546)=4.08, p<$ .001; and if they had worse performance on Flanker incongruent trials, $t(508)=3.00, p=.003$.

A total of 84 students (15\%) were missing academic achievement test scores in 2015. Students were more likely to have missing achievement data in 2015 if they were Asian/Pacific Islander, $t(564)=2.04$, 
$p=.042$ (relative to White/Caucasian); were female, $t(567)=2.35, p$ $=.019 ;$ and were older, $t(567)=3.70, p<.001$.

\section{Analytic strategy}

Multiple imputation using chained equations was used to address missing data (van Buuren, 2012). A total of 20 data sets were imputed using a single-level imputation model that included classroom fixed effects (Drechsler, 2015). Analyses were run on each imputed data set separately, and parameter estimates were pooled across imputations. We used multilevel modeling to test $\mathrm{CP}$ as a predictor of mathematics and ELA achievement. In all models, demographic covariates included age, gender, race/ethnicity, and parental educational attainment. We centered CP and EFs around each classroom's mean to rule out selection into classrooms as a potential confound. Effect sizes were quantified using the change in model $R^{2}$ (Nakagawa \& Schielzeth, 2013).

\section{Results}

\section{Bivariate associations}

Correlations and descriptive statistics are presented in Table 1. CP was positively correlated with directly assessed EFs $(r=.21, p<$ .001) and teacher-reported EFs ( $r=.09, p=.002)$. Directly assessed EFs and teacher-reported EFs were positively correlated with each other $(r=.31, p<.001)$. CP and both measures of EFs were positively associated with all measures of achievement ( $r$ s ranged from .28 to $.53, p s<.001)$. Older students reported greater levels of CP ( $r$ $=.09, p=.002)$ and had better performance on direct assessments of EFs $(r=.20, p<.001)$, earlier ELA achievement tests $(r=.07 \cdot p$ $=.014$ ), and later mathematics and ELA achievement tests ( $r \mathrm{~s}=.20$ and .27, respectively, $p s<.001)$. Girls reported lower levels of CP than boys ( $r=.11, p<.001)$, were reported by teachers as having better EFs ( $r=.34, p<.001)$, and had slightly better ELA achievement test scores in 2013 and 2015 ( $r$ s $=.09$ and .12, $p=.003$ and $p$ $<$.001, respectively). Finally, parental educational attainment was positively associated with $\mathrm{CP}(r=.18, p<.001)$, performance on 
Table 1 Correlations and descriptive statistics.

\begin{tabular}{|c|c|c|c|c|c|c|c|c|c|c|}
\hline & 1 & 2 & 3 & 4 & 5 & 6 & 7 & 8 & 9 & 10 \\
\hline 1. Challenge preference & - & & & & & & & & & \\
\hline 2. EFs, directly assessed & $.21^{*}$ & - & & & & & & & & \\
\hline 3. EFs, teacher reported & $.09 *$ & $.31^{*}$ & - & & & & & & & \\
\hline 4. Mathematics (2013) & $.28^{*}$ & $.43^{*}$ & $.38^{*}$ & - & & & & & & \\
\hline 5. English language arts (2013) & $.30 *$ & $.47^{*}$ & $.39 *$ & $.75^{*}$ & - & & & & & \\
\hline 6. Mathematics (2015) & $.33^{*}$ & $.51^{*}$ & $.40^{*}$ & $.75^{*}$ & $.71^{*}$ & - & & & & \\
\hline 7. English language arts (2015) & $.28^{*}$ & $.53^{*}$ & $.43^{*}$ & $.62^{*}$ & $.75^{\star}$ & $.81^{*}$ & * - & & & \\
\hline 8. Child age (years) & $.09 *$ & $.20^{\star}$ & .01 & .02 & $.07 *$ & $.20^{*}$ & $.27^{*}$ & - & & \\
\hline 9. Female child & $-.11^{*}$ & $.06^{*}$ & $.34^{*}$ & -.01 & $.09^{*}$ & -.01 & $.12^{*}$ & $-.10^{\star}$ & - & \\
\hline 10. Parent education (years) & $.18^{*}$ & $.18^{*}$ & $.10^{*}$ & $.29^{*}$ & $.39 *$ & $.38^{*}$ & $.39 *$ & $.07^{*}$ & -.04 & - \\
\hline Mean or \% & 0.73 & 0.00 & 0.10 & 409.20 & 365.17 & 2512.91 & 2502.94 & 9.88 & $50 \%$ & 13.76 \\
\hline Standard deviation & 0.29 & 1.00 & 0.96 & 91.85 & 69.06 & 88.26 & 95.77 & 0.83 & - & 3.44 \\
\hline Skewness & -0.87 & -1.26 & -0.07 & 0.22 & 0.20 & 0.01 & -0.11 & 0.09 & - & -0.48 \\
\hline
\end{tabular}

EF: executive function.

${ }^{*} p<.05$ using the Benjamini-Hochberg adjustment for multiple testing (Benjamini \& Hochberg, 1995).

direct assessments of EFs ( $r=.18, p<.001)$, teacher-reported EFs $(r=.10, p=.001)$, and academic achievement ( $r$ s ranged from .29 to $.39, p s<.001)$.

\section{Multilevel models for mathematics and English language arts}

We used intraclass correlations (ICCs) to quantify the proportion of variance in academic achievement at the classroom level. ICCs were .23 for mathematics and .25 for ELA. EFs and CP were centered around each classroom's mean to obtain an unbiased estimate of the withinclassroom (i.e., student-level) associations (Enders \& Tofighi, 2007); this procedure is equivalent to the inclusion of classroom fixed effects and rules out selection effects because we are estimating only withinclassroom effects, not between-classroom effects.

In our first set of models, we did not control for prior achievement. These models provide information about whether-and to what degree-CP was associated with students' academic achievement while controlling for the set of covariates. Model 1A included school fixed effects and the following demographic covariates: parents' educational attainment and students' gender, age, and race/ethnicity. Model 1B added student EFs (direct assessments and teachers' reports) to Model 
1A. In our second set of models, we added controls for prior achievement to understand the role that $\mathrm{CP}$ plays in predicting change in achievement; Models 2A and 2B added prior achievement to Models $1 \mathrm{~A}$ and $1 \mathrm{~B}$, respectively.

\section{Predicting academic achievement}

A baseline model (Model 1A) that included school fixed effects and demographic covariates explained $33.5 \%$ of the variance in mathematics and $35.2 \%$ of the variance in ELA. When CP was added to this model, it was positively associated with mathematics $(\beta=.20, S E=$ $.02, p<.001)$ and ELA $(\beta=.15, S E=.03, p<.001)$. CP increased the model $R^{2}$ by $3.6 \%$ (to $37.1 \%$ ) for mathematics and by $2.3 \%$ (to $37.4 \%$ ) for ELA.

We estimated a second baseline model (Model 1B) that included student EFs in addition to school fixed effects and demographic covariates. This model explained $48.8 \%$ of the variance in mathematics and $52.0 \%$ of the variance in ELA. When CP was added to this model (see Table 2), it was positively associated with mathematics ( $\beta=.14, S E$ $=.02, p<.001)$ and ELA $(\beta=.09, S E=.02, p<.001) . \mathrm{CP}$ increased the model $R^{2}$ by $1.8 \%$ (to $50.6 \%$ ) for mathematics and by $0.7 \%$ (to $52.7 \%)$ for ELA.

Table 2 Multilevel regression analyses predicting academic achievement without controls for prior achievement.

\begin{tabular}{|c|c|c|c|c|c|c|}
\hline & \multicolumn{3}{|c|}{ Mathematics } & \multicolumn{3}{|c|}{ English Language Arts } \\
\hline & $\beta$ & $(S E)$ & $p$ & $\beta$ & (SE) & $p$ \\
\hline Intercept & 0.16 & $(0.18)$ & .358 & 0.07 & $(0.17)$ & .680 \\
\hline Female childa & -0.19 & $(0.05)$ & $<.001$ & 0.09 & $(0.05)$ & .056 \\
\hline African American/Black & -0.63 & $(0.11)$ & $<.001$ & -0.60 & $(0.11)$ & $<.001$ \\
\hline Hispanic/Latino ${ }^{a, b}$ & -0.42 & $(0.08)$ & $<.001$ & -0.25 & $(0.08)$ & .001 \\
\hline Asian/Pacific Islander & 0.03 & $(0.08)$ & .709 & -0.12 & $(0.08)$ & .104 \\
\hline Other/multiraciala,b & -0.19 & $(0.11)$ & .096 & -0.18 & $(0.10)$ & .067 \\
\hline Child age (years) & 0.09 & $(0.04)$ & .040 & 0.15 & $(0.04)$ & $<.001$ \\
\hline Parent education (years) & 0.10 & $(0.03)$ & $<.001$ & 0.12 & $(0.03)$ & $<.001$ \\
\hline EFs, directly assessed & 0.21 & $(0.03)$ & $<.001$ & 0.23 & $(0.03)$ & $<.001$ \\
\hline EFs, teacher reported & 0.30 & $(0.03)$ & $<.001$ & 0.30 & $(0.03)$ & $<.001$ \\
\hline Challenge preference & 0.14 & $(0.02)$ & $<.001$ & 0.09 & $(0.02)$ & $<.001$ \\
\hline
\end{tabular}

$E F s=$ executive functions. Models also control for school fixed effects.

a. Coefficients for dummy codes are standardized for the dependent variable only.

b. Reference category is "White/Caucasian." 
Predicting change in academic achievement

For this analysis, our first baseline change model (Model 2A) included school fixed effects, demographic covariates, and prior achievement test scores. This model explained $62.8 \%$ of the variance in mathematics and $65.3 \%$ of the variance in ELA. While controlling for these covariates (see Table 3), CP was positively associated with change in mathematics $(\beta=.07, S E=.02, p<.001)$ but was unrelated to change in ELA $(\beta=.00, S E=.02, p=.977)$. Adding CP increased the model $R^{2}$ by $0.4 \%$ (to $63.2 \%$ ) for mathematics.

We estimated a second baseline change model (Model 2B) that included student EFs in addition to school fixed effects, demographic covariates, and prior achievement test scores. This model explained $64.9 \%$ of the variance in mathematics and $67.3 \%$ of the variance in ELA. When CP was added to this model, it remained a significant predictor of change in mathematics achievement $(\beta=.06, S E=.02, p=$ .002) and did not predict change in ELA achievement $(\beta=.00, S E=$ $.02, p=.910)$. For mathematics, CP increased the model $R^{2}$ by $0.3 \%$ (to $65.2 \%$ ).

Table 3 Multilevel regression analyses predicting academic achievement with controls for prior achievement.

\begin{tabular}{|c|c|c|c|c|c|c|}
\hline & \multicolumn{3}{|c|}{ Mathematics } & \multicolumn{3}{|c|}{ English Language Arts } \\
\hline & $\beta$ & $(S E)$ & $p$ & $\beta$ & $(S E)$ & $p$ \\
\hline Intercept & 0.00 & $(0.16)$ & .996 & -0.06 & $(0.17)$ & .709 \\
\hline Prior Achievement & 0.47 & $(0.02)$ & $<.001$ & 0.49 & $(0.02)$ & $<.001$ \\
\hline Female childa & -0.06 & $(0.05)$ & .224 & 0.09 & $(0.04)$ & .024 \\
\hline African American/Black ${ }^{a, b}$ & -0.37 & $(0.10)$ & $<.001$ & -0.51 & $(0.11)$ & $<.001$ \\
\hline Hispanic/Latino ${ }^{a, b}$ & -0.22 & $(0.07)$ & $<.001$ & -0.09 & $(0.06)$ & .175 \\
\hline Asian/Pacific Islander & 0.06 & $(0.06)$ & .360 & -0.04 & $(0.06)$ & .554 \\
\hline Other/Multiracial| & -0.14 & $(0.10)$ & .148 & -0.12 & $(0.09)$ & .156 \\
\hline Child age (years) & 0.17 & $(0.04)$ & $<.001$ & 0.15 & $(0.04)$ & $<.001$ \\
\hline Parent education (years) & 0.05 & $(0.03)$ & .086 & 0.06 & $(0.03)$ & .025 \\
\hline EFs directly assessed & 0.10 & $(0.02)$ & $<.001$ & 0.09 & $(0.03)$ & $<.001$ \\
\hline EFs teacher reported & 0.13 & $(0.03)$ & $<.001$ & 0.14 & $(0.03)$ & $<.001$ \\
\hline Challenge preference & 0.06 & $(0.02)$ & .002 & 0.00 & $(0.02)$ & .910 \\
\hline
\end{tabular}

$E F$, executive function. Models also control for school fixed effects.

a. Coefficients for dummy codes are standardized for the dependent variable only.

b. Reference category is "White/Caucasian." 
Sensitivity analyses

We conducted two sets of sensitivity analyses (Duncan, Engel, Claessens, \& Dowsett, 2014). First, we repeated the analyses without centering within classroom; our results were not substantively changed by the choice of centering method. Second, previous research suggests that the validity of questionnaire measures can be compromised for younger children (Borgers, de Leeuw, \& Hox, 2000). Because $\mathrm{CP}$ was measured using 8- to 12-year-olds' self-reports, we tested age as a moderator of the relation between $\mathrm{CP}$ and academic achievement. This interaction was not related to ELA or mathematics achievement, indicating that the predictive validity of students' self-reported CP did not differ between younger and older students.

\section{Discussion}

The goal of this investigation was to understand the role of $\mathrm{CP}$ for elementary school students' academic achievement. Our findings are consistent with previous studies showing that students' self-reported CP (Altermatt \& Pomerantz, 2005; Soto, 1988) and a broader intrinsic motivation construct that includes CP (Broussard \& Garrison, 2004; Goldberg \& Cornell, 1998; Lepper et al., 2005) are significantly related to academic outcomes. Extending this work, we showed that CP is a prospective longitudinal predictor of students' performance on standardized achievement tests. We also found that CP and EFs were independent predictors of academic achievement, supporting a theoretical model of self-regulated learning in which intrinsic motivation and cognitive skills jointly contribute to learning (McCombs \& Marzano, 1990; Zimmerman \& Schunk, 2011).

The unique contribution of challenge preference and executive functions

Intrinsic motivation and EFs have rarely been studied together, especially in upper elementary school grades. As a result, we lack even basic descriptive knowledge about the bivariate associations between $\mathrm{CP}$ and EFs during this developmental period. We found positive 
correlations between CP and EFs, which affirms the need to study these constructs together to understand their unique associations with achievement. Accounting for EFs as a potential confound reduced the associations between $\mathrm{CP}$ and academic achievement by $50 \%$ or morebut did not completely eliminate the unique effects of $\mathrm{CP}$.

The inclusion of CP and multiple measures of EFs in the same model is also useful because it allows us to compare the relative effect sizes for each construct. This comparison revealed that unique effects were largest for teacher-reported EFs, followed by directly assessed EFs and CP. Although teacher-reported EFs are designed to measure students' EF-related behaviors in the classroom, they are also influenced by teacher-child relationships, students' demographic characteristics, and teachers' prior knowledge of students' academic achievement (Garcia et al., 2019). It is likely that teacher-reported EFs capture a variety of students' experiences in the classroom that contribute to academic achievement.

The importance of challenge preference for academic achievement

Our study showed that students' CP was uniquely related to their performance on both mathematics and ELA achievement tests over and above the significant contributions of students' age, gender, and race/ethnicity-as well as parents' educational attainment, teachers' reports of EF classroom behaviors, and direct assessment of EF skills. However, our CP measure significantly predicted 2-year longitudinal change only for mathematics test scores. This divergent finding between mathematics and ELA could be due to the content of our CP assessment. The CP scale that we used in this study was composed of items about students' preferences for challenging games, tasks, puzzles, and problems. It is possible that the content of our measure (e.g., puzzles) is more relevant to solving math problems than it is to ELA. One important direction for future research will be to understand whether $\mathrm{CP}$ is a unidimensional construct or whether there are meaningful distinctions among specific domains of CP (e.g., academic, sport, art) that can be linked to achievement in different areas. Understanding the underlying structure of CP would inform educators' efforts to promote it in school settings.

Further, there is a need to better understand how $\mathrm{CP}$ is related to other aspects of intrinsic motivation such as growth mindset-the 
belief that abilities are malleable rather than fixed. Persistence in the face of challenges has long been studied as an outcome in growth mindset experiments (Dweck, 1991). For example, growth mindset instructions have been shown to increase persistence in an educational game, particularly among struggling students (O'Rourke, Haimovitz, Ballweber, Dweck, \& Popović, 2014). To our knowledge, researchers have not studied associations between $\mathrm{CP}$ and growth mindset in the absence of experimental manipulation and have not examined these two aspects of intrinsic motivation together in order to understand which one is a stronger predictor of academic achievement. Clarifying the degree to which $\mathrm{CP}$ and other aspects of motivation differentially promote positive student outcomes can both advance our understanding of the structure of the intrinsic motivation construct and guide approaches to fostering intrinsic motivation in elementary school students.

To contextualize the effect sizes for $\mathrm{CP}$, we look to other motivational constructs that have been studied much more extensively. For example, meta-analyses indicate that the average bivariate correlation $(r)$ with academic achievement (i.e., in the absence of any control variables) is only .10 $\left(R^{2}=1.0 \%\right)$ for growth mindset (Sisk, Burgoyne, Sun, Butler, \& Macnamara, 2018) and .13 $\left(R^{2}=1.7 \%\right)$ for mastery goal orientation (Huang, 2012). For comparison, the correlations between $\mathrm{CP}$ and achievement in our study were substantially larger: .33 for math and .28 for ELA. The effect size for CP from the multilevel models is difficult to compare to previous research because of the unique set of covariates used in this study.

It is important to note, however, that the rigorous analytic approach used in this study provides a conservative estimate of the relations between $\mathrm{CP}$ and academic achievement. First, by using multilevel models that include school fixed effects and by centering the predictors within each classroom, we were able to rule out alternative explanations for the findings-such as selection effects. This is particularly important because sociodemographic characteristics such as income and race show strong clustering effects at the school level in the United States (Orfield, Ee, Frankenberg, \& Siegal-Hawley, 2016; Owens, Reardon, \& Jencks, 2016), where this study was conducted. Because of our analytic approach, CP could not explain any between-classroom variance. Second, obtaining increases in the model $R^{2}$ becomes progressively more difficult as the amount of variance explained by other 
predictors increases. Simply put, there is less unique variance in the dependent variable that is left to be explained by additional predictors. This is most notable for analyses in which we control for prior academic achievement because of the extremely strong longitudinal relations between achievement test scores (Adachi \& Willoughby, 2015). Therefore, it is not surprising that $\mathrm{CP}$ explained a modest amount of unique variance in students' achievement score change over time.

\section{Challenge preference: Measurement implications}

Our measure of $\mathrm{CP}$ was short (i.e., five questions) and used a binary response scale. This approach was similar to other child surveys assessing mindsets (e.g., Cain \& Dweck, 1995). This developmentally appropriate format helped to ensure that elementary school students understood the questions and could provide valid responses. Indeed, sensitivity analyses indicated that our results did not depend on age, suggesting that younger and older students understood the questions equally well. In contrast to our measures of EFs, which incorporated students' performance on four tasks as well as teachers' reports, our sole measure of $\mathrm{CP}$ was based on students' self-reported responses to hypothetical situations. It is possible that direct assessments of CP would have greater validity or would provide additional predictive utility.

There is a pressing need to develop and validate scalable direct assessments of intrinsic motivation. Extant direct assessments of $\mathrm{CP}-$ such as having children choose whether they would like to do a task that they know they can do (i.e. that makes them think a little) or a task that is more challenging (i.e. that makes them think a lot)-have previously been used only in preschool samples (Howse et al., 2003; Smiley \& Dweck, 1994; Stipek \& Ryan, 1997). These existing tasks use only one or two questions, and information about their reliability and validity is lacking. Adapting and expanding on these measures for use in elementary school and beyond would help to scale up research on the development of intrinsic motivation and its relation with academic achievement with larger and more representative samples. A multiinformant approach could also prove to be useful; currently, there are no validated teacher or parent report scales to measure child CP. 
Challenge preference: Implications for classroom practice

Motivational characteristics-such as $\mathrm{CP}$-are particularly attractive as intervention targets because treatment can be brief, inexpensive, and scalable (Lazowski \& Hulleman, 2016; Paunesku et al., 2015). For example, interventions targeting students' mindsets can be effective in as little as a single session (Sisk et al., 2018). Prior research demonstrates that students display more $\mathrm{CP}$ and persistence when teachers praise students' effort rather than their intelligence (Mueller \& Dweck, 1998). An experiment similarly showed that children exhibited significantly more persistence on a challenging puzzle task when they were provided with process praise (e.g., "You must have tried really hard") compared with when they were provided with person praise (e.g., "You're really good at this") (Kamins \& Dweck, 1999). Therefore, teacher feedback focused on effort encourages students to persist when learning activities are difficult-which is particularly important during the upper elementary school years, when academic demands are significantly higher. Our results suggest that this kind of feedback could have benefits for students' achievement via increases in students' CP.

Furthermore, autonomy support in the classroom has been positively linked to children's intrinsic motivation, including CP (e.g., Bartholomew et al., 2018; Ciani, Middleton, Summers, \& Sheldon, 2010). Autonomy support is a broad term encompassing teacher practices such as listening to student perspectives, providing rationale for teacher requests, and allowing students to give input and feedback on learning activities (Cheon, Reeve, Lee, \& Lee, 2018). A meta-analysis of autonomy support interventions for teachers demonstrates that a relatively brief session (1-3 hours) focused on skill-based activities can significantly increase autonomy support in classrooms (Su \& Reeve, 2011). Further, autonomy support interventions for teachers have been successful at improving students' intrinsic motivation (Guay, Valois, Falardeau, \& Lessard, 2016; Hastie, Rudisill, \& Wadsworth, 2013; Tessier, Sarrazin, \& Ntoumanis, 2010). Changing classroom environments could help to mitigate documented declines in children's intrinsic motivation and CP as they age (Harter, 1981; Lepper et al., 2005) and support children's challenge seeking through the middle childhood years. 
In comparison with interventions targeting students' mindsets (Paunesku et al., 2015), EF interventions tend to be more time and resource intensive (Diamond \& Ling, 2016), suggesting that educational interventions targeting $\mathrm{CP}$ or other aspects of intrinsic motivation may have a more favorable cost-benefit ratio than EF interventions.

\section{Limitations}

In addition to measurement issues discussed above, the current study had several limitations. First, the measures of CP and directly assessed EFs had relatively low estimates of reliability. Measurement error could result in an underestimate of the effect size of the relations between CP and EFs as well as their associations with achievement. Conversely, measurement error could lead to overestimates of the unique associations between each construct and achievement because of inadequate statistical controls. In future work, a latent variable approach could mitigate the effects of measurement error. Second, because $\mathrm{CP}$ was measured only once, we were unable to test bidirectional relations between achievement and CP. Researchers have shown that academic achievement can predict intrinsic motivation (Bronstein et al., 2005; Garon-Carrier et al., 2016). One direction for future research will be to understand whether academic achievement is prospectively related to change in CP. Third, we examined EFs as a unitary construct because only four EF tasks were included in this study. Ideally, researchers would examine CP together with three EF skill domains (i.e., inhibitory control, cognitive flexibility, and working memory), especially because working memory is believed to be particularly important for math achievement (Friso-van den Bos, van der Ven, Kroesbergen, \& van Luit, 2013).

\section{Conclusion}

Children who seek out challenges are believed to have more opportunities to learn and grow their skills (Elliott \& Dweck, 1988). That view is supported by the findings from this prospective longitudinal study. Even while controlling for students' demographic characteristics and EFs, CP was associated with mathematics and ELA achievement, and it predicted change in mathematics achievement. The next 
steps for this line of research are to test whether interventions and teaching strategies that promote $\mathrm{CP}$ in elementary school students also benefit academic achievement.

Acknowledgments This research was supported by a William T. Grant Foundation Scholar award (180826) and by a Jacobs Foundation Advanced Research Fellowship to Jelena Obradović and a William R. and Sara Hart Kimball Stanford Graduate Fellowship to Jenna Finch. The authors thank the students, teachers, and school administrators who participated and made this research possible, and they thank the many graduate and undergraduate students who helped to collect and process the data. The findings, conclusions, and opinions here are those of the authors and do not represent views of the William T. Grant Foundation or the Jacobs Foundation.

\section{Appendix}

Executive functioning vignette

(C) Jelena Obradović (2013)

Please read the following vignette and then rank your students. Put the student name who is best described by the vignette first and the student name who is most poorly described by the vignette last:

This child easily adjusts to a new situation such as a change of teachers or class plans. S/he is also good at accepting new ways to solve a problem with schoolwork or friends. This child is good at remembering activities that include several steps and is able to finish them without being prompted or reminded. This child has good control over her/ his actions-follows classroom rules (e.g., stays in assigned seat, raises hand), doesn't interrupt others, and knows how to take turns. This child is good at staying focused on a difficult or repetitive task. S/he is not easily distracted by irrelevant noises and sights. This child's backpack and desk are organized and s/he is good at keeping track of homework, permission slips, and lunch money. This child is careful and always checks work for mistakes. 


\section{References}

Adachi, P., \& Willoughby, T. (2015). Interpreting effect sizes when controlling for stability effects in longitudinal autoregressive models: Implications for psychological science. European Journal of Developmental Psychology, 12, $116-128$.

Altermatt, E. R., \& Pomerantz, E. M. (2005). The implications of having highachieving versus low-achieving friends: A longitudinal analysis. Social Development, 14, 61-81.

Anderman, E. M., \& Midgley, C. (1997). Changes in achievement goal orientations, perceived academic competence, and grades across the transition to middlelevel schools. Contemporary Educational Psychology, 22, 269-298.

Annie E. Casey Foundation (2010). Early warning! Why reading by the end of third grade matters [special report]. Baltimore, MD: Author.

Bartholomew, K. J., Ntoumanis, N., Mouratidis, A., Katartzi, E., ThøgersenNtoumani, C., \& Vlachopoulos, S. (2018). Beware of your teaching style: A school-year-long investigation of controlling teaching and student motivational experiences. Learning and Instruction, 53, 50-63.

Benjamini, Y., \& Hochberg, Y. (1995). Controlling the false discovery rate: A practical and powerful approach to multiple testing. Journal of the Royal Statistical Society: Series B (Methodological), 57, 289-300.

Borgers, N., de Leeuw, E., \& Hox, J. (2000). Children as respondents in survey research: Cognitive development and response quality. Bulletin of Sociological Methodology, 66, 6o-75.

Bronstein, P., Ginsburg, G. S., \& Herrera, I. S. (2005). Parental predictors of motivational orientation in early adolescence: A longitudinal study. Journal of Youth \& Adolescence, 34, 559-575.

Broussard, S. C., \& Garrison, M. E. (2004). The relationship between classroom motivation and academic achievement in elementary-school-aged children. Family and Consumer Sciences Research Journal, 33, 106-120.

Bush, G., \& Shin, L. M. (2006). The Multi-Source Interference Task: An fMRI task that reliably activates the cingulo-frontal-parietal cognitive/attention network. Nature Protocols, 1, 308-313.

Cain, K. M., \& Dweck, C. S. (1995). The relation between motivational patterns and achievement cognitions through the elementary school years. MerrillPalmer Quarterly, 41, 25-52.

Cheon, S. H., Reeve, J., Lee, Y., \& Lee, J. (2018). Why autonomy-supportive interventions work: Explaining the professional development of teachers' motivating style. Teaching and Teacher Education, 69, 43-51.

Ciani, K. D., Middleton, M. J., Summers, J. J., \& Sheldon, K. M. (2010). Buffering against performance classroom goal structures: The importance of autonomy support and classroom community. Contemporary Educational Psychology, 35, 88-99. 
Corpus, J. H., \& Wormington, S. V. (2014). Profiles of intrinsic and extrinsic motivations in elementary school: A longitudinal analysis. Journal of Experimental Education, 82, 480-501.

Davidson, M. C., Amso, D., Anderson, L. C., \& Diamond, A. (2006). Development of cognitive control and executive functions from 4 to 13 years: Evidence from manipulations of memory, inhibition, and task switching. Neuropsychologia, 44, 2037-2078.

Developmental Studies Center. (n.d.). Scales from student questionnaire, Child Development Project for elementary school students (Grades 3-6). Alameda, CA. Retrieved from https://www.collaborativeclassroom.org/resources/scalesfrom-student-questionnaire-child-development-project-for-elementary-schoolstudents-grades-3-6/

Diamond, A., \& Ling, D. S. (2016). Conclusions about interventions, programs, and approaches for improving executive functions that appear justified and those that, despite much hype, do not. Developmental Cognitive Neuroscience, 18 , 34-48.

Drechsler, J. (2015). Multiple imputation of multilevel missing data-Rigor versus simplicity. Journal of Educational and Behavioral Statistics, 40, 69-95.

Duncan, G. J., Engel, M., Claessens, A., \& Dowsett, C. J. (2014). Replication and robustness in developmental research. Developmental Psychology, 50, 2417-2425.

Dweck, C. S. (1991). Self-theories and goals: Their role in motivation, personality, and development. In R. A. Dienstbier (Ed.). Nebraska symposium on motivation 1990 (Vol. 38, pp. 199-235). Lincoln: University of Nebraska Press.

Eccles, J. S., \& Wigfield, A. (2002). Motivational beliefs, values, and goals. Annual Review of Psychology, 53, 109-132. Educational Testing Service. (2014). California Standards Tests: Technical report: Spring 2013 administration. Retrieved from https://star.cde.ca.gov/techreports/CST/cst13techrpt.pdf

Elliott, E. S., \& Dweck, C. S. (1988). Goals: An approach to motivation and achievement. Journal of Personality and Social Psychology, 54, 5-12.

Enders, C. K., \& Tofighi, D. (2007). Centering predictor variables in crosssectional multilevel models: A new look at an old issue. Psychological Methods, 12, 121-138.

Felton, K. A., \& Akos, P. (2011). The ups and downs of third grade. Educational Leadership, 68, 28-31.

Finch, J. E., \& Obradović, J. (2017). Independent and compensatory contributions of executive functions and challenge preference for students' adaptive classroom behaviors. Learning and Individual Differences, 55, 183-192.

Flanagan, D. P., \& Kaufman, A. S. (2009). Essentials of WISC-IV assessment (2nd ed.). Hoboken, NJ: John Wiley.

Friso-van den Bos, I., van der Ven, S. H., Kroesbergen, E. H., \& van Luit, J. E. (2013). Working memory and mathematics in primary school children: A metaanalysis. Educational Research Review, 10, 29-44. 
Fuhs, M. W., Farran, D. C., \& Nesbitt, K. T. (2015). Prekindergarten children's executive functioning skills and achievement gains: The utility of direct assessments and teacher ratings. Journal of Educational Psychology, 107, 207-221.

Gaderman, A. M., Guhn, M., \& Zumbo, B. D. (2012). Estimating ordinal reliability for Likert-type and ordinal item response data: A conceptual, empirical, and practical guide. Practical Assessment, Research, \& Evaluation, 17(3), 1-13.

Garcia, E. B., Sulik, M. J., \& Obradović, J. (2019). Teachers' perceptions of students' executive functions: Disparities by gender, ethnicity, and ELL status. Journal of Educational Psychology, 111, 918-931.

Garon-Carrier, G., Boivin, M., Guay, F., Kovas, Y., Dionne, G., Lemelin, J.-P., ... Tremblay, R. E. (2016). Intrinsic motivation and achievement in mathematics in elementary school: A longitudinal investigation of their association. Child Development, 87, 165-175.

Goldberg, M. D., \& Cornell, D. G. (1998). The influence of intrinsic motivation and self-concept on academic achievement in second- and third-grade students. Journal for the Education of the Gifted, 21, 179-205.

Guay, F., Valois, P., Falardeau, É., \& Lessard, V. (2016). Examining the effects of a professional development program on teachers' pedagogical practices and students' motivational resources and achievement in written French. Learning and Individual Differences, 45, 291-298.

Harter, S. (1981). A new self-report scale of intrinsic versus extrinsic orientation in the classroom: Motivational and informational components. Developmental Psychology, 17, 300-312.

Hastie, P. A., Rudisill, M. E., \& Wadsworth, D. D. (2013). Providing students with voice and choice: Lessons from intervention research on autonomy-supportive climates in physical education. Sport, Education and Society, 18, 38-56.

Howse, R. B., Lange, G., Farran, D. C., \& Boyles, C. D. (2003). Motivation and selfregulation as predictors of achievement in economically disadvantaged young children. Journal of Experimental Education, 71, 151-174.

Huang, C. (2012). Discriminant and criterion-related validity of achievement goals in predicting academic achievement: A meta- analysis. Journal of Educational Psychology, 104, 48-73.

Kamins, M. L., \& Dweck, C. S. (1999). Person versus process praise and criticism: Implications for contingent self-worth and coping. Developmental Psychology, 35, 835-847.

Lawson, G. M., Hook, C. J., Hackman, D. A., \& Farah, M. J. (2014). Socioeconomic status and neurocognitive development: Executive function. In J. A. Griffin, L. S. Freund, \& P. McCardle (Eds.), Executive function in preschool children: Integrating measurement, neurodevelopment, and translational research (pp. 1-28). Washington, DC: American Psychological Association Press.

Lazowski, R. A., \& Hulleman, C. S. (2016). Motivation interventions in education: A meta-analytic review. Review of Educational Research, 86, 602-640. 
Lee, K., Bull, R., \& Ho, R. M. (2013). Developmental changes in executive functioning. Child Development, 84, 1933-1953.

Lepper, M. R., Corpus, J. H., \& Iyengar, S. S. (2005). Intrinsic and extrinsic motivational orientations in the classroom: Age differences and academic correlates. Journal of Educational Psychology, 97, 184-196.

McCombs, B. L., \& Marzano, R. J. (1990). Putting the self in self-regulated learning: The self as agent in integrating will and skill. Educational Psychologist, 25, 51-69.

Miles, S. B., \& Stipek, D. (2006). Contemporaneous and longitudinal associations between social behavior and literacy achievement in a sample of low-income elementary school children. Child Development, 77, 103-117.

Mueller, C. M., \& Dweck, C. S. (1998). Praise for intelligence can undermine children's motivation and performance. Journal of Personality and Social Psychology, 75, 33-52.

Nakagawa, S., \& Schielzeth, H. (2013). A general and simple method for obtaining $R^{2}$ from generalized linear mixed-effects models. Methods in Ecology and Evolution, 4, 133-142.

Nelson, T. D., Nelson, J. M., James, T. D., Clark, C. A., Kidwell, K. M., \& Espy, K. A. (2017). Executive control goes to school: Implications of preschool executive performance for observed elementary classroom learning engagement. Developmental Psychology, 53, 836-844.

Nguyen, T., \& Duncan, G. J. (2019). Kindergarten components of executive function and third grade achievement: A national study. Early Childhood Research Quarterly, 46, 49-61.

Obradović, J., Sulik, M. J., Finch, J. E., \& Tirado Strayer, N. (2018). Assessing students' executive functions in the classroom: Validating a scalable groupbased procedure. Journal of Applied Developmental Psychology, 55, 4-13. doi:10.1016/j.appdev.2017.03.003

Orfield, G., Ee, J., Frankenberg, E., \& Siegal-Hawley, G. (2016). Brown at 62: School segregation by race, poverty and state. Los Angeles: The Civil Rights Project, University of California, Los Angeles.

O’Rourke, E., Haimovitz, K., Ballweber, C., Dweck, C., \& Popović, Z. (2014). Brain points: A growth mindset incentive structure boosts persistence in an educational game. Proceedings of the 32nd Annual ACM Conference on Human Factors in Computing Systems-CHI '14 (pp. 3339-3348). doi:10.1145/2556288.2557157

Owens, A., Reardon, S. F., \& Jencks, C. (2016). Income segregation between schools and school districts. American Educational Research Journal, 53, 1159-1197.

Paunesku, D., Walton, G. M., Romero, C., Smith, E. N., Yeager, D. S., \& Dweck, C. S. (2015). Mind-set interventions are a scalable treatment for academic underachievement. Psychological Science, 26, 784-793. 
Reardon, S. F. (2011). The widening academic achievement gap between rich and poor: New evidence and possible explanations. In G. J. Duncan \& R. J. Murnane (Eds.), Whither opportunity? Rising inequality, schools, and children's life chances (pp. 91-115). New York: Russell Sage.

Sisk, V. F., Burgoyne, A. P., Sun, J., Butler, J. L., \& Macnamara, B. N. (2018). To what extent and under which circumstances are growth mind-sets important to academic achievement? Two meta-analyses. Psychological Science, 29, 549-571.

Smarter Balanced Assessment Consortium. (2016). Smarter Balanced Assessment Consortium: 2014-15 technical report. Retrieved from https://portal. smarterbalanced.org/library/en/2014-15-technical-report.pdf

Smiley, P. A., \& Dweck, C. S. (1994). Individual differences in achievement goals among young children. Child Development, 65, 1723-1743.

Soto, L. D. (1988). The motivational orientation of higher- and lower-achieving Puerto Rican children. Journal of Psychoeducational Assessment, 6, 199-206.

Stipek, D. J., \& Ryan, R. H. (1997). Economically disadvantaged preschoolers: Ready to learn but further to go. Developmental Psychology, 33, 711-723.

Su, Y.-L., \& Reeve, J. (2011). A meta-analysis of the effectiveness of intervention programs designed to support autonomy. Educational Psychology Review, 23, 159-188.

Sulik, M. J., \& Obradović, J. (2018). Teachers' rankings of children's executive functions: Validating a methodology for school-based data collection. Journal of Experimental Child Psychology, 173, 136-154. doi:10.1016/j.jecp.2018.01.016

Tessier, D., Sarrazin, P., \& Ntoumanis, N. (2010). The effect of an intervention to improve newly qualified teachers' interpersonal style, students' motivation and psychological need satisfaction in sport-based physical education. Contemporary Educational Psychology, 35, 242-253.

Toplak, M. E., West, R. F., \& Stanovich, K. E. (2013). Practitioner review: Do performance-based measures and ratings of executive function assess the same construct? Journal of Child Psychology and Psychiatry, 54, 131-143.

Tuominen-Soini, H., Salmela-Aro, K., \& Niemivirta, M. (2012). Achievement goal orientations and academic well-being across the transition to upper secondary education. Learning and Individual Differences, 22, 290-305.

van Buuren, S. (2012). Flexible imputation of missing data. Boca Raton, FL: CRC Press.

Wrzesniewski, A., Schwartz, B., Cong, X., Kane, M., Omar, A., \& Kolditz, T. (2014). Multiple types of motives don't multiply the motivation of West Point cadets. Proceedings of the National Academy of Sciences of the United States of America, 111, 10990-10995.

Zelazo, P. D., Anderson, J. E., Richler, J., Wallner-Allen, K., Beaumont, J. L., \& Weintraub, S. (2013). II. NIH Toolbox Cognition Battery (CB): Measuring executive function and attention. Monographs of the Society for Research in Child Development, 78(4), 16-33. 
Zelazo, P. D., Blair, C. B., \& Willoughby, M. T. (2016). Executive function: Implications for education (No. NCER 2017-2000). Washington, DC: National Center for Education Research, Institute of Education Sciences, U.S. Department of Education.

Zimmerman, B. J. (1986). Becoming a self-regulated learner: Which are the key subprocesses? Contemporary Educational Psychology, 11, 307-313.

Zimmerman, B. J., \& Schunk, D. H. (Eds.). (2011). Handbook of self-regulation of learning and performance. New York: Routledge. 